\title{
Graduate students share their experiences of building helping skills: A case study
}

\author{
Michael Houdyshell ${ }^{1}$ \& Natasha Ziegler ${ }^{2}$
}

1. Corresponding author

Florida Gulf Coast University, College of Education, Fort Myers, United States

E-mail: mhoudyshell@fgcu.edu

2. Florida Gulf Coast University, College of Education, Fort Myers, United States

\section{Article Info}

Received: June 15, 2020

Revised: September 25, 2020

Accepted: October 25, 2020

\section{$10.46303 / j c s r .2020 .4$}

\section{How to cite}

Houdyshell, M. \& Ziegler, N. (2021).

Graduate students share their experiences of building helping skills: A case study. Journal of Curriculum Studies Research, 3(2), 57-78. https://doi.org/10.46303/jcsr.2020.4

\section{Copyright license}

This is an Open Access article distributed under the terms of the Creative Commons Attribution 4.0 International license.

https://creativecommons.org/licenses/by/4.0/

\begin{abstract}
Higher education needs individuals working with students to have the skills to handle a variety of issues related to success and wellbeing. Graduate programs preparing higher education professionals to work with students provide the opportunity for skill-building to occur. However, how do graduate students perceive their skill development in courses offered in a graduate program, specifically related to basic helping skills? This study, conducted in a College of Education at a university located in the Southern United States, posed two questions to find out more about the attributes graduate students contribute in the development of their knowledge of helping skills and to document the lived experiences of graduate students practicing helping skills. Five graduate students, enrolled in a new course on helping skills, were part of this case study. Three themes emerged after collecting and coding data during the course. The three themes were: building helping skills, confidence and comfortability, and multicultural, diversity and inclusion. The discussion section includes recommendations to offer a helping skills course in graduate programs to prepare individuals for working in higher education. Courses on helping skills should always include a multicultural focus, and the course curriculum should include a mix of clinical and practical elements.

\section{KEYWORDS}

Helping skill; Higher education graduate programs; Student affairs preparation programs; Curriculum; Case study
\end{abstract}




\section{INTRODUCTION}

College-age students are often under great duress and experience a chronic or sudden mental health crisis, but they are not inclined to seek professional assistance (Massey et al., 2014; Novotney, 2014). For this reason, higher education staff should be trained in helping skills so they can recognize and reach out to students who are struggling (Council for the Advancement of Standards in higher education (CAS), 2012; Protivnak et al. 2013; Reynolds, 2011). Access to these skills is no longer limited to counseling programs, and they can be utilized to strengthen the skills of Higher Education professionals.

Many institutions now have helping skills courses within a variety of graduate, noncounselor education programs. Basic helping skills training for higher education professionals to assist college students who may be struggling emotionally and mentally is an important component of our educational systems (Becker et al., 2002; Lipson et al., 2014; Mitchell et al., 2012; Reynolds, 2011). Staff must know how to identify signs of mental and emotional instability and how to respond appropriately to those students.

Little is known about student perceptions of the preparation of helping skills in noncounselor education programs (Jaeken et al., 2017; Reynolds \& Altabef, 2015). It is important to document the learning experiences of these students as they prepare for future careers that will require the daily practice of these skills (Reynolds \& Altabef, 2015). Because this focus on helping skills in non-counselor education programs is fairly recent, it is important to learn if what is taught and how it is being taught are adequately preparing them for interacting with students, especially with those who are struggling emotionally and psychologically.

This study follows the recommendation by Reynolds (2013) to investigate the components of a course on helping skills in "Exploring the ways that graduate students are taught about helping skills throughout the curriculum will provide educators the tools to determine where the gaps are and how current courses may need to be redesigned or new courses may need to be developed" (p. 230). With this in mind, the researchers sought to document and describe the complexity and effectiveness of a new helping skills course offered for higher education professionals at a university. In doing so, the purpose of this study is to understand the experiences of students in an Educational Leadership graduate program at a midsized university located in Southwest Florida, who were enrolled in a new helping skills course. As part of the study, the researchers completed a review of the assertions about the level of preparedness students possessed coming into and during the course. The results of this study could also develop a framework for other graduate programs to assess their helping skills course curriculums for non-counseling professionals.

\section{College Students and Mental Health}

Many higher education professionals working in student affairs, housing and residence, student services, as well as faculty, report interacting with students who are experiencing mental health difficulties (Becker et al. 2002; Lipson et al., 2014; Mitchell et al., 2012; Moss, 2017; Reynolds, 
2013). Researchers have found that mental health difficulties were among one of the issues facing college students, as well as a lack of professional training on practicing appropriate methods of intervention (Becker et al., 2002; Mitchell et al., 2012; Reynolds, 2011). However, researchers have shown that most higher education staff and faculty are not trained to identify or respond to students with mental health difficulties or able to refer them to the appropriate student support services (Becker et al., 2002; Mitchell et al., 2012; Reynolds, 2011). In several institutions, helping skills and counseling courses for prospective student affairs professionals have been incorporated into their graduate programs (Protivnak et al., 2013; Reynolds, 2013). The Florida institution utilized for this study has chosen to provide the resources of a helping skills course to both present and future higher education professionals.

\section{On Campus Mental Health Resources}

Today there is a demand for institutional counseling professionals to conduct informational programs on preventative mental distress practices for students and professionals, as well as accessing students' wellbeing (Francis \& Horn, 2017). In addition, an alarming rise in the inability to even access existing mental health services on campus because of increasing wait times, is becoming an issue. A 2016-17 survey released by the Association for University and College Counselors Center Directors reported $34 \%$ of centers had to place students on a waitlist to receive mental health services (Burwell, 2018). Moss (2017) found that colleges and universities are experiencing daily difficulties of connecting students to immediate campus supports and resources for individuals who are struggling with academic or personal difficulties. Trela (2008) reminds professionals that there is not only a focus on the individual student during each instance of a crisis but also the impact on other students whom they are connected to, which may also explain the increase in needs. A survey completed by a population of student affairs professionals found that mental health was listed as a difficulty for students and a concern for professionals on taking appropriate steps toward intervention as more students come forward (Reynolds, 2013).

Astin (1993), in his early work on college student persistence and retention, found that the transition to college can lower psychological well-being. However, most students will not utilize psychological counseling offered at the institution. There is a stigma to attending counseling in higher education and some students are less likely to know or connect with counseling centers in college (Massey et al., 2014; Protivnak et al., 2013). Stigma still exists despite researchers reporting that relations and connections with higher education professionals show a positive influence on students overall academic success, positive attitude, and motivation within education (Astin, 1993; Martin \& Siefert, 2011). Also, training for frontline staff that provides the ability to recognize and assist students with mental health crises can improve the likelihood of those students connecting with the appropriate support resources on campus, such as counseling centers (Massey et al., 2014; Novotney, 2014). Thus, to assist students, it is important to provide educational training and courses for higher education professionals (Becker et al., 2002; Moss, 2017; Reynolds, 2011; Trela, 2008). Training and educational 
opportunities may even have a positive impact on professionals' and students' attitudes towards students who have difficulties with mental health (Becker et al., 2002; Massey et al., 2014). Some researchers encourage going beyond training and continuing different efforts of collaboration between institution counseling centers and other higher education personnel (Moss, 2017; Novotney, 2014).

\section{Mental Health Helpers}

Okun and Kantrowitz (2015) clarified the difference between professional helpers, those who serve as psychiatrists, psychologists, and mental health counselors in clinical settings, who obtain certifications through in-depth practicums within their graduate program, and what are termed "next level helpers." Next level helpers are described as general human services workers, traditionally providing services when professional helpers are not in the position to provide immediate support. When describing the expectations and roles of helpers, whether professional or next level, any person striving to assist others with difficulties require a certain level of skill. Helping skills are appropriate for those in positions of support and referral to mental health departments (Okun \& Kantrowitz, 2015).

Helping skills are traditionally defined as micro-skills, focusing on listening, paraphrasing, attending behaviors, and showing empathy (Egan, 2013; Reynolds, 2011). These skills can also be described as advanced helping skills that allow for short-term helping and the development of rapport (Okun \& Kantrowitz, 2015). Helping skills are important for effective interactions for those practicing as helpers and making connections with clients (Egan, 2013; Moss, 2017). Reynolds (2009) and Burke et al. (2016) recommend the specific use of helping skills to assist students in this area should be taught within graduate programs and possibly professional staff training.

\section{Helping Skills and Higher Education Professionals}

Student affairs professionals are already working with students to recognize mental health difficulties and connecting to appropriate resources during the normal course of performing their regular roles on campus as student affairs professionals (Burke et al., 2016; Reynolds, 2013). Additionally, college students interact frequently with a multitude of supporting offices on university and college campuses that already provide support, and with proper training, they would act as an additional resource for mental health assistance (Massey et al., 2014; Protivnak et al., 2013). In a Delphi study on entry-level competencies of new Student Affairs professionals, Burkard et al., (2004) observed that graduate programs for these professionals would benefit from participating in graduate courses in relatable fields, including counseling, business, and computer science. This Delphi study was utilized to build a common understanding of the needed skills and knowledge for entry-level student affairs professionals. Out of the 32 competencies, problem-solving ranked $7^{\text {th }}$, counseling/active listening ranked $11^{\text {th }}$ and multicultural competency ranked $12^{\text {th }}$, as they relate to the content of a Helping Skills course (Burkard et al., 2004). 
Simply being able to identify that students are experiencing difficulties is not enough. Trela (2008) noted that when higher education professionals act as frontline responders, it is important to know basic counseling skills. College and university administration, as well as counseling departments, have been encouraged to collaborate in creating preparation programs for future higher education professionals with skills focused on helping students who are experiencing a personal crisis (Stark \& Weinbaum, 2018). The lack of proper training for higher education professionals related to identifying, communicating, and appropriately referring students dealing with psychological difficulties creates an overall negative effect on student success within institutions (Becker et al., 2002; Trela, 2008). Likewise, Moss (2017) argued that the higher education professionals trained in micro-counseling skills must remember the importance of practicing referring within their professional scope. Reynolds (2011) believed that the simple proof in the rise of mental health difficulties should concern a college and university; enough to encourage leaders to implement the support needed for professionals to learn new skills.

\section{Helping Skills Training and Graduate Programs}

Reynolds's (2009) book on helping skills has been utilized for courses within Student Affairs graduate programs. Burke et al. (2016) also published Helping skills for working with college students, applying counseling theory to Student Affairs practice, supporting the implementation of helping skills training for professionals within higher education. The unique benefit to teaching helping skills as opposed to or in addition to Mental Health First Aid (MHFA) training are the different populations these helping skills can assist. MHFA trainings provide undergraduate and graduate students, as well as staff and faculty at higher education institutions, with skills to identify students experiencing mental health difficulties and how to mak appropriate referrals to counseling centers. However, a course or training on basic helping skills not only benefits professionals working in higher education, but also broadens the scope of their interactions with students on issues such as mental health challenges, cultural competencies, working with other professionals, training, and multicultural competencies (Burke et. al., 2016; Reynolds, 2009).

In addition to the Helping Skills text by Reynolds, there was a Delphi study on student affairs professionals, that collected information on the skills needed to work within the student affairs profession. Reynolds (2011) reported on specific skills identified in the Delphi study, which included helping skills, on the job training, and professional development opportunities. In this study, traditional helping and micro-counseling skills including listening, reframing, goal setting, etc. were identified to advance helping skills (Reynolds, 2011). In a review of the Council for the Advancement of Standards in Higher Education (CAS Professional Standards), Protivnak et al. (2013) identified departments within university and college settings that need assessment and training support for micro-counseling skills, building upon Reynolds (2011) work. It is noted that continued study is encouraged by some researchers in identifying which recent discrepancies exist in the CAS Professional Standards skills recommended for areas of higher 
education, and the degree of what administration and professionals are currently employing daily (Protivnak et al., 2013).

More recently, Reynolds and Altabef (2015) reviewed syllabi related to the teaching of helping skills in graduate programs such as education, counseling, and student affairs. The results showed that many of the courses were missing educational information related to common mental health issues such as signs of suicide interventions and eating disorders (2015). When offering a helping skills course, Reynolds and Altabef (2015) encouraged the use of quantitative and qualitative studies to assess the comfort level, understanding, competence, and in-depth understanding of participants. Both Reynolds and Altabef (2015), as well as Protivnak et al. (2013), encourage continued research at institutions that do and do not have helping skills training for higher education professionals. Burkard et al. (2004) recommended that graduate programs for future student affairs professionals also evaluate their programs as they relate to expected competencies for the field. At the institution used for this current study, there are no existing courses that teach helping skills or education on the mental health crisis in higher education for prospective student affairs or higher education professionals. In this context, this study would investigate the quality and effectiveness of the curriculum in a higher education course at a midsized university located in southwest Florida.

Helping skills courses are provided in graduate programs for future counselors, human service workers (e.g. social workers, nurses, life coaches, etc.), and higher education programs. Research by Banks et al. (2016) provides information relating to mindfulness and gaining people's trust through the practice of a three-tiered model of mindfulness integration within a basic helping skills course for human service workers. Their research reviewed a theoretical practice within the course, detailing a great level of support for incorporating mindfulness practices into helping skills courses. Gockel and Burton (2014) studied 132 students within a graduate social work program, reviewing their helping skills training which was offered within foundational courses. In their findings, the student participants reported an increase in their self-efficacy of practicing counseling skills while participating in the training and thus benefited from the helping skills training (Gockel \& Burton, 2014). Grockel and Burton (2014) described the three most preferred instructional strategies as identified by the student participants; instructor practice examples, live demonstrations, and videotaped reviews.

The researchers explored the answers for two research questions related to the experience of graduate students in a new course on helping skills as follows:

1. What attributes do graduate students contribute in the development of their knowledge of helping skills as future higher education professionals while enrolled in a helping skills graduate course?

2. What are the lived experiences of graduate students practicing helping skills within a hybrid graduate course design? 


\section{METHODOLOGY}

Dr. Houdyshell teaches in both the Masters and Doctoral programs, with an emphasis in topics relating to higher education. He has worked for 20 years in higher education administration including with college students in a variety of settings. This sometimes includes working with students experiencing personal crises influenced by at times, unresolved issues with mental health, and employing helping skills. More recently, studying the topic of helping skills in more detail while working together with Natasha Ziegler in creating a new course on helping skills for a Master's program for professionals working in higher education.

Natasha Ziegler was an Academic Success Coach and second-year doctoral student in an educational leadership program at the time of the study, and served as the co-creator and teaching assistant for the helping skill course. She has worked in the Center for Academic Achievement for six years, helping students improve their academic performance within their undergraduate courses. Having earned her Master's in School Counseling, she is familiar with micro counseling skills and mental health counseling. For the past three years, she has trained new incoming Academic Success Coaches on helping skills, identifying students struggling with mental health, and making appropriate referrals to Counseling resources.

The researchers used a qualitative case study to gather information and data for this case study (Creswell, 2013; Yazan, 2015; Yin, 2014). The case study approach was used for this research because it lends itself to detailed analysis and descriptors, in this case of a single environment, with the opportunity for a rich and in-depth discussion in a real-life context (Baxter \& Jack, 2008). The researchers wanted to describe the experience of students enrolled in a new graduate course on helping skills offered by a small college of education at a four-year mid-level university in Florida, making it an intrinsic case study for the newness to the program. Creswell and Poth, (2018) describe intrinsic case study as the study of a unique situation. It was conducted over one term in a hybrid delivery method focusing on creating and practicing helping and supporting skills for current and future work with students and colleagues in higher education. The study group was selected with purposeful sampling, using only the five students enrolled in the course during one specific semester. Participants included five master's level students, and one Doctoral student serving as the Teaching Assistant in the spring 2018 term, of which, all but one worked at a university at the time of the study. Data collected involved responses to open-ended questions, in-class discussions, and personal reflections. Discussion questions were posted online with supplemental questions and reflections for more objective results. Content analysis was used to gather and report results (Kohlbacher, 2006). No human subjects permissions were obtained because this study was conducted as part of evaluating a new course in the Educational Leadership graduate program.

While this study is localized, both researchers view this study has an important examination into the thoughts and beliefs of how graduate students and higher education professionals view helping skills, how they gain helping/supporting skills, and how they might be better prepared to support students in their roles on campus or in the future. The results are 
intended to be disseminated at the institution where the case study was conducted in a current climate of major institutional initiatives involving the examination of supporting students, including academic success, retention, and graduate rates. The data could also be used as continued support for the inclusion of a helping skills course and/or training in graduate programs training higher education professionals.

\section{Participants}

As stated above, five master's level students who enrolled in the course during the spring 2018 term were used as the sample in the study. These participants were chosen as part of purposeful sampling. Purposeful sampling was used because all of the students were already in the helping skills course as an elective, it is less time consuming to gather data for the case study, and the course is taught over four months which allows for ample time to continue gathering data with the ability to refine questions (Stake, 2005). All five were current graduate students in the Educational Leadership program in the College of Education at the time of the course. This was a special topics course being offered for the first time, so all of the students selected this course as an elective in their graduate program. Four of the students were currently employed in higher education, working with students in some capacity. The one student not currently employed in higher education at the time of the study has since graduated and is now working as an academic advisor at a university. Finally, of the five students, four were female and one was male, three were Caucasian, and two were students of color. All students gave written permission for use of the data to study the need, benefit, and structure of the course as this course would be offered in future terms.

\section{Data Collection and Analysis}

The course on helping skills was taught primarily online but had five pre-scheduled face-to-face class meetings throughout the term. During these five in-class meetings, all the students were asked both structured and unstructured questions in a class discussion setting and were asked to participate in role-playing activities to practice different levels of helping skills and support. These questions dealt with topics such as how to gain helping skills, individual beliefs about helping skills, opinions about how higher education professionals use helping skills, and rating their preparedness being able to perform helping and support skills at the beginning of the course and the end.

Students were asked to share their expected outcomes from the course as it related to using helping and support skills in the future or strengthening their practice as a higher education professional throughout their on-line and in-class coursework. Students used two required textbooks: 1. "Helping College Students: Developing Essential Support Skills for Student Affairs Practice" (Reynolds, 2009), and 2. "Helping Skills: Facilitating Exploration, Insight, and Action" (Hill, 2014) during the entire course. Both textbooks were supplemented with additional readings by both authors and others, and writing about helping and supporting skills. Finally, each student was asked to prepare two final papers for the end of the course. The first paper was a reflection on the evolution of their thinking and the use of helping and supporting skills 
when working with students. The second paper dealt with creating a personal theory of helping they would use in any future practice as a higher education professional when working with students.

At the end of the course, all students were sent a Student Perception of Instruction (SPol) course evaluation. This general evaluation is voluntary for students in a course. Each instructor has the option to add up to five additional and specific questions to this survey instrument. Five questions were added to the end of the SPol related to this research study. No IRB was sought as the instructor was asking the students to evaluate the course while trying to understand how higher education professionals gain and use helping and supporting skills in their work with students through the delivery of the course. Again, all students gave written permission for the use of the data for this case study as this course would be offered in future terms.

\section{Rigor}

This study employed the method of data collecting using triangulation. Using triangulation as a data collection method allows the researcher to create validity in the study with the utilization of multiple data sources (Hussein, 2009). In reviewing data, all responses to in-class questions, final reflection papers, and personal theory of helping, were hand-written and/or reviewed after submission. Responses to online discussion questions and the SPol questions were also reviewed after each submission. Using a content analysis approach, the researcher is able to systematically categorize textual and conversational data to make sense of it (Forman \& Damschroder, 2007). In addition, using unstructured interview questions during three of the five in-class sessions allowed the researchers to ask questions with further inquiry based on realtime responses. The researchers utilized content analysis to review online responses and probe further with additional questions, allowing each student to reflect and respond at their own pace. Content analysis allowed the researchers to identify and construct important themes from the data review (Creswell \& Poth, 2018). Using coding with grouping and sub-groupings, the researchers compared emerging theme clusters before ultimately creating three themes (Vaismoradi et al., 2016).

In this study, the in-class discussions and responses were the preferred method of inquiry. In order to perform an in-depth case study, there must be a collection of many forms of qualitative data (Creswell \& Poth, 2018). This data, combined with document analysis of the online responses to posted questions including the SPol, and the evaluation of posted course assignments (reflection paper and personal theory of helping), increased study validity through the use of data triangulation (Hussein, 2009). After the course was completed, in-class discussion responses, online discussion responses, final papers, and course evaluation questions were all analyzed for specific themes using content analysis. The entire set of data produced individual participant and study themes, which were then analyzed for relevancy and presented in this case study.

In this study, the role of the researcher was as the instructor for the course where participants were enrolled, and one graduate assistant who assisted with course design. The 
primary researcher wrote and analyzed all discussions, both online and in-class, online questions and responses, course papers, and evaluation questions. He attempts to present the findings and discussion as it is reported and coded without the interjection of his own views. Any personal opinions and other findings outside of the coded information are presented in the discussion section.

To ensure the validity and reliability of the study, the researchers utilized the following procedures:

a) Data triangulation-All findings have been presented based on in-class discussions, online discussion questions and responses, course assignments, and final course evaluation questions. After each in-class session, students were able to review questions and responses online and provide feedback individually to the researcher or as a posted online discussion question/response. This allowed students to amend any comments or provide further clarification for the researcher and fellow students in the course. This was a 15- week course that allowed for multiple and deep interactions with some participants, and repeated attempts at clarification of data.

b) Direct quotations have been used where necessary and appropriate when presenting the findings. All data were reviewed for the reporting phase to reach common conclusions on findings, and possible codes and themes were then determined.

\section{RESULTS}

In review of the data, including the pre and post helping skills survey and, the SPol, there were many overlapping themes and lessons learned. The results provided in this section are derived from the students' final reflection assignment, post helping skills survey results, and the SPol (completed at the conclusion of the course). In the initial review of the data, four themes emerged; however, through further review of participant responses discussing two topics within the same discussion, the themes Diversity and Inclusion, and Multiculturalism were combined into one theme. In the following sections, we will provide qualitative information on the data we collected relating to the following themes; Building Helping Skills, Confidence, and Comfortability, and Multicultural, Diversity, and Inclusion.

\section{Building Helping Skills}

During the helping skill course used for this study, students completed a variety of assignments including reflection journals, discussion boards, fill in the blank responses, presentations, and group role-play. For some of the assignments, the Hill textbook was utilized with positive feedback from the students. Some of the students found the framework of the different helping skills practices helpful to learn and practice:

...the online activities were a chance to practice and solidify my helping skills." (Jessica, Final Reflection, 2019). 
I appreciated the online activities where we could work out different responses that we could give within (each) phase of Hill's three-stage helping model (2014). Conducting this exercise for immediacy, challenges, open questions for insight, interpretations, disclosures of insight or feelings, restatements, open questions about thoughts and feelings, and reflections of feelings was a good way to practice using these skills before doing the inclass role-playing activity and helping skills practice demo project (Sara, Final Reflection, 2019).

Many others found it helpful to reflect in their journals on experiences in and outside of the classroom, what they learned in the readings, and their interpretations of the theories:

The journal entries provided me with the opportunity to reflect, revise, and review my own perspectives about helping and allowed me to integrate the theories and skills that we learned in class with real-life situations. (Jessica, Final Reflection, 2019)

The journals were a great way to reflect on readings and some of the in-class role-plays were good for integrating and practicing the skills that we learned about. (Anonymous, SPol, 2019)

In addition to the journals and practice assignments, students had the opportunity to conduct group role-play scenarios in class and a final demo assignment that consisted of a roleplay with a classmate as a video submission:

Over this course, we participated in several in-class role-playing activities and ended with the video presentation with our partner. I feel that with each activity, I became more comfortable. (Erica, Final Reflection, 2019).

The helping skills practice demo assignment supported my learning the most. As uncomfortable as it was, the in-class role-playing and this assignment are the best ways to practice helping skills. (Anonymous, SPol, 2019).

The in-class role-playing and helping skills practice demo helped most in familiarizing myself with the different skills. (Anonymous, SPol, 2019)

An assignment mentioned frequently, was the Inclusive Helper because it challenged the students to consider culture and mental health influences on their own usage of helping skills. "I also thought the Inclusive Helper was a great way to integrate the learning we had been doing and apply it to specific examples. (Anonymous, SPol, 2019).

Beyond practicing and using helping skills within the course, several students noted the practice and use of helping skills in other parts of their professional and personal lives. This demonstrated the application of helping skills in different aspects of participants' lives:

This course has provided me the ability to utilize my skill set off-campus. I have been involved in a local youth ministry in (name of city). I have always been a helper for many youths in the ministry. This course has helped me strengthen my character for the advancement of my personal growth (Anonymous, Post Self-Assessment, 2019). 
Another student saw a direct use for the helping skills she was learning in the course and shared some of her materials with students she mentored: "(I) gave them my training based on the knowledge I gained in this helping skills course" (Sara, Final Reflection, 2019).

\section{Confidence and Comfortability}

At the beginning of this course, many of the students reported mixed responses when selfreporting their confidence in practicing helping skills. The majority of the participants ranked their ability to practice the skills very highly, while others ranked the confidence very low. When utilizing the pre and post-assessment on the comfort of utilizing helping skills, many of the participants showed little difference in their self-rankings of comfort. However, the postassessment showed more change in how students expressed how they had developed a great deal of confidence compared to the pre-assessment. One participant reflected on the possible over-exaggeration of their pre-assessment confidence in their ability to practice helping skills:

Before the course, I was not very confident in practicing helping skills." (Anonymous, SPol, 2019).

I think I might have a little bit less confidence in my skills, but I think my original confidence was somewhat unearned. I consider myself someone who has decent emotional intelligence and interpersonal intelligence, so I was confident that helping skills would come naturally. Turns out, I probably need just as much practice as everyone else, but I do feel like I have more knowledge to move forward with (Anonymous, SPol, 2019).

Conducting my own research about students who face mental health struggles and creating a presentation that accurately portrayed what a student with a mental illness might face on campus as well as resources for best helping those students was eyeopening [...] it also taught me about advocacy and how to stand up for and support students with diverse and varying characteristics (Jessica, Final Reflection, 2019).

As a result of participating in the course, many of the students expressed a sense of gratitude for the unique experience that influenced their confidence and comfort levels when practicing helpings skills:

Understanding the experimental, insight, and action stage makes me more comfortable to address students. (David, Post-Assessment, 2019).

I feel much more confident helping not only students, but people in general as a result of taking this course. (Erica, Post-Assessment, 2019).

I certainly feel more confident with my helping skills now. (Anonymous, SPol, 2019).

Very high-(I) want to do my internship specifically practicing these skills. (Anonymous, SPol, 2019).

[...] (I) felt more comfortable understanding how to help someone make sense of their own problems and situations. It has been me more comfortable with who I am and my style of helping. It helped me realize that I make sense when I am comforting others, so be confident in my abilities and speak everything with conviction (Kimberly, PostAssessment, 2019). 
Many of the participants made comments that reminded the future helpers that helping skills are ever-evolving through multiple stages and experiences.

I believe that the more I continue to practice my helping skills, the better helper I will become. (Erica, Final Reflection, 2019).

I don't think any of my professional experience really prepared for or affected my confidence level in practicing helping skills. I hadn't been in a role that was particularly helping focused. (Anonymous, SPol, 2019).

\section{Multicultural, Diversity, and Inclusion}

As noted in the Building Helping Skills section above, assignments and discussions were designed to challenge the students to consider how a student's culture and mental health could impact their use of helping skills. Many of the students reflected on what they learned through these opportunities.

Culture has a lot to do with the effects of a helper towards their students. It presents the ability for the helper to understand certain behaviors and responses that they collect from the students [...] Cultures are constantly evolving, and as helpers, we have to remain aware of the cultural changes (David, Final Reflection, 2019).

One student reflected on the importance of culture awareness when working within Higher education:

[...] understanding different cultures is extremely important to helpers in higher education. The inclusive helper presentations helped me to learn about different cultures" (Erica, Final Reflection, 2019).

The student clarified that while progressing through the course they were not only able to learn about helping skills, but also learn more about underserved populations:

I have learned questioning techniques, goal-setting, self-awareness, and disclosure. I have also gained great insight into different student populations, including multicultural, firstgeneration, non-traditional, LGBTQ+ and low-income students, to name a few. (Erica, PostAssessment, 2019).

The design of this course is representative of the ability to include both helping skills and cultural awareness in the process.

The assignments were designed to align with using helping skills in general areas, but also to demonstrate how the higher education setting is a unique venue for practicing these skills. Some participants who currently work in higher education expressed the importance of using this new knowledge in their current and future work in higher education.

The focus that we gave to certain issues related to mental health, such as awareness of suicidal intentions, being honest and calm in meetings, and how different populations are affected by the issue, were helpful for me to learn, for my current position and future career in higher education (Sara, Final Reflection, 2019). 
I know the needs for understanding different cultures, how higher education is changing and the mental health issues arising with our students. With this wealth of knowledge that I have gained, I am ready to assist students and their needs (Erica, Final Reflection, 2019).

\section{DISCUSSION}

Reynolds and Altabef (2015) have emphasized the importance of collecting qualitative research of student experiences within helping skills courses in a Higher Education and Student Affairs preparation program. With the existing literature supporting the need for helping skills training for developing professionals in this field, little research has been completed that tells the lived experiences of the participants while enrolled in such a course. The responses from the students in this course support a continued narrative about why learning helping skills in higher education graduate programs is still essential.

Professional competencies for individuals working in student affairs positions have been crafted and revised by professional organizations like the National Association of Student Personnel Administrators (NASPA) and the American College Personnel Association (ACPA). Both organizations published a joint statement and professional competencies originally in 2010 with an update in 2015 (ACPA, 2010; 2015). The Joint Task Force on Professional Competencies and Standards reviewed documents produced by ACPA, NASPA, and the Council for the Advancement of Standards in Higher Education (CAS) and proposed ten competency areas (2015). Of the ten competency areas proposed, one specifically influences the work from this case study in how graduate students and professionals in higher education gain and utilize helping and supporting skills. Originally this specific competency area was termed Advising and Helping, and has since been renamed Advising and Supporting in part to emphasize 'the agency of college students in their development of self-authorship" $(2015$, p. 5). The task force continues, "We also intend to better distinguish the role of student affairs educators from those of counselors, psychologists, nurse practitioners, among others" (p. 5). They continue, "we acknowledge this line is not easy to draw...even in student affairs roles that require a degree in counseling, individuals within those roles do not provide therapeutic or formal helping services" (p. 5). However, the authors still recognize "through developing advising and supporting strategies...we play critical roles in advancing the holistic wellness of ourselves, our students, and our colleagues" (2015, p. 36). By including helping and supporting skills/strategies as one of the ten original professional competency areas, the framers of these competencies understood how integral this set of skills for working with students but also to ourselves and those around us.

The data from this study support the inclusion of helping and supporting skills within the original ten professional competencies for student affairs professionals, although graduate students in a higher education program are still unsure of how they gain and utilize these skills. DiRamio (2014) cited how these competencies help guide curriculum decisions and course 
learning outcomes. If the professional competencies are being applied in graduate programs in their preparation of new professionals (Gansemer-Topf \& Ryder, 2017), is that application entirely clear to students in these programs, and how do they utilize these competencies once studied as new or emerging professionals in higher education? How higher education professionals, new or otherwise, gain and utilize this important competency in helping and supporting students is still not clearly defined or understood. The results of this study help support continued application of advising and support in competencies for student affairs professionals and graduate students.

Jaeken et al. (2017) found that participants in helping skills training have under-assessed themselves, exhibiting some self-diminishment bias in their ability to practice helping skills. This research supports the study results as some participants expressed high confidence in their ability to practice helping skills in the pre-assessment, but then reported lower confidence levels after participating in the course. Participant responses described a pattern of students selfactualizing while practicing the skills and areas in need of improvement not initially known to them.

The need for coursework related to a standard of professional studies, in this case counseling, or at the very least listening and reflection, have been found as important competencies when administrators are seeking to hire professionals working in student affairs (Kretovics, 2002). Reynold's (2011) Delphi studies support the inclusion of learning basic helping skills as an important piece of student affairs professionals' daily practice. The research conducted in this study support this research as the student participants expressed how important it is for many of them to build these skills. The present use of the techniques was also discussed for the students who are currently serving in student affairs positions.

Students within this course expressed an appreciation for in-class role-play and practice with classmates as a strong contributor to their ability to develop the helping skills. It allowed for immediate feedback and practice with others who were also progressing through the learning experience. Similar to Gockel and Burton's (2014) research on helping skills Training for Graduate Social Work students, many of the students in this study referenced the instructor's modeling of the helping skills and practicing within the training as a preferred method of learning and a key contributor to their development. The idea of 'learning by doing' (also called experiential learning) in the form of strategies like role-playing, has been documented in the literature as an effective means of achieving learning gains (Bradberry \& De Maio, 2018; Oros, 2007; Raymond, 2010).

In a review of helping skills courses created specifically for current or future student affairs professionals, Reynolds and Altabef (2015) found educational issues, such as mental health, were often a missing component in how students and professionals develop appropriate skills for handling personal and mental health concerns. The course utilized for this study included coursework on mental health and multicultural awareness as it relates to the practice of helping skills. Participants expressed an appreciation for not simply learning the helping skills techniques 
but developing an understanding of how mental health and cultural awareness can influence the practice of these skills. Research on mental health literacy shows that when students understand more about their mental health, they are better able to listen and empathize with others in their mental health (Carr et al., 2017; Kutcher et al., 2015; Kutcher et al., 2016).

\section{CONCLUSION}

\section{Graduate Programs for Higher Education Professionals}

This course is offered as an elective in a Master's program on Educational Leadership. While the program is not exclusively focused on individuals who are or will work in student affairs positions, examining and enhancing helping skills positively impacts any individual working with college students. The ability to listen, understand, empathize, and assist where appropriate, cannot be overstated when working with college students, regardless of position. At present, the specific course used in the case study is only offered as an elective because it was brand new when the study was conducted. The Master's program the course is housed under already exists, but as more students enroll with a student affairs background or interest, the need for such a course continues to grow. That is even more apparent for graduate programs focused entirely on creating new student affairs professionals.

Including a required helping skills course in master's programs in higher education with a student affairs emphasis, and counseling only covers a small fraction of human service-related graduate programs offered in higher education. While the results from this study and others support the inclusion of this type of course, it is not clear if students enrolled, show markedly different approaches to assisting others. Future studies on the efficacy and comfortability of students using these skills after completing a helping skills course would further strengthen the need for requiring this course in a larger number of graduate programs, diversifying and broadening its acceptance in other human service type graduate programs. This includes using different research studies to understand different methods designed to produce a similar outcome in assisting individuals, such as a solution-focused method, often taught in counseling graduate programs (Stark \& Weinbaum, 2018).

\section{Multicultural Focus}

Courses on helping skills are often based on psychological and counseling theories created years earlier and applied to work in other areas. Application to fields such as student affairs have occurred much later. As college students have become much more diverse in their backgrounds and beliefs (ethnically, socioeconomically, religiously, etc.), it is important that individuals working with college students find ways to relate and apply their training or background in helping skills to the changing face of college students today and tomorrow. This includes adding a significant multicultural and inclusiveness component to any existing course on helping skills, or even creating a complimentary helping skills course that focuses entirely on the topic. Additionally, a course might even offer practice and skill-building within topics like social justice, 
income disparities, and global competencies. A recent study by Lu et al. (2020), using students in two helping skills courses, showed gains in ethnocultural empathy after helping skills training from the course, primarily for white students (both male and female). As with the course for this study, Lu et al. (2020) also based their course on Hill's helping skills textbook. With any course on helping skills building, building rapport among participants is key. According to Lu et al. (2020), as a result, a helping skills course "may provide a structure of interaction that affords the learning of key skills in developing empathy about social inequalities..." (p. 9).

\section{Mix of Clinical and Practical}

The textbooks used in the course were different in their approaches to how students learn helping skills. Hill's textbook is based on a more clinical approach to developing helping skills, as Hill is a licensed Counseling professional. In contrast, the textbook by Reynold, is written with a less clinical focus and instead examines learning helping skills from a practitioner's viewpoint, especially for student affairs professionals. Reynold's is also a licensed psychologist. Using the combination of both textbooks for this course creates a dynamic where some clinical aspects of mental health as it relates to helping skills (Hill), is more accessible. Hill's work is based on her model of helping which includes three stages for working with a client-exploration, insight, and action (2019). Both Hill and Reynolds provide scenarios in each textbook. Reynolds also includes additional information on role-playing exercise. This course employed a blend of both the review of helping skills in a clinical setting and role-playing of the same helping skills. Participants reported this as a more desirable way to learn about helping skills, and understand how to apply them in their own non-clinical practice. Research has also shown that some experiential learning techniques like role-playing, can reduce the anxiety of students learning about helping skills in a skills-based course (Hall, 2009; Hill et al., 2007; Tolleson et al., 2017).

While the researchers advocate creating a helping skills course that features both clinical and practical approaches to learning helping skills, we are cognizant this approach is limited to the experiences and backgrounds of faculty who teach the course within only one program. Moving beyond the inclusion of including both clinical and practical materials in a helping skills course, we urge higher education administration graduate program faculty, and counseling graduate program faculty to jointly create and teach courses in helping skills as supported by the research of Stark and Weinbaum (2018). This can produce higher education professionals who have a more diverse and rich experience learning and practicing helping skills in collaborative course design. Specific to the design and creation of the helping skills course used for this study, the experience of one researcher is primarily in student affairs, while the other individual has a graduate degree in counseling. The collaboration began even before the creation of the course. When looking to design and add this course to the Master's program in Educational Leadership, Dr. Houdyshell sought out collaboration with a fellow faculty member in the Counseling Master's program. That faculty member was not able to collaborate because of prior commitments but supported the idea of including a helping skills course outside of a counseling graduate program, and recommended working with a recent graduate of the 
counseling program who worked on campus. This collaboration was a significant catalyst behind the creation of the helping skills course, and subsequent case study, and it should be seen as a model in creating a helping skills course.

\section{Size}

A limitation of this study was the small number of participants. As this was only one course on helping skills during one term, additional students over subsequent terms could impact the results of the study. Because of this, the generalizability of the study to other graduate student experiences and programs presents a possible limitation on the results. However, there is prior research on this topic where these results can help support past results and conclusions.

\section{Elective Enrollment}

Students who decide to enroll in an elective course on helping skills are already predisposed to be more interested in developing these kinds of abilities for their work in higher education. It does not make their experience or responses any less valid and can create an environment of increased self-awareness and identification of deficiencies in their helping skills knowledge and practice. In a higher education environment of increasing barriers to student success, additional awareness, practice, and reflection by current or future student affairs professional warrants continued contemplation, and perhaps even additional study on the efficacy of these types of courses. Finally, for a more in-depth analysis of this topic, the addition of individual and group interviews would strengthen the validity and richness of any results. Relying on self-reported or submitted responses creates an important snapshot of the topic. Incorporating interviews would add significant depth to the study not found otherwise.

\section{Richer Analysis}

Future studies may need to design questions that focus on specifics of practice, rather than the participants' opinion of their ability, to allow for a more accurate self-assessment measurement. This could best be accomplished by adding personal interviews and focus group sessions with participants. This type of data measure would allow future studies to more accurately gauge the proficiency in using a course on helping skills to enhance their own skill level.

As college students arrive on campus, they bring with them different life experiences and issues impacting their lives while also trying to navigate the complexities of higher education. Professionals working in higher education are often responsible for helping students make sense of their experiences while in college. These same professionals must balance their professional responsibilities with also providing emotional and personal support to students. Many of these same professionals do not receive formal training about how best to support students emotionally in a non-clinical setting. Without any formal training, it can be challenging to understand how best to approach these situations. This should be the role of graduate programs that offer courses on learning, developing, and practicing helping skills. Helping skills courses should provide both the necessary foundations in which to learn about best practices, and a safe space to practice these skills. Without access to helping skills courses, higher education 
professionals are left to learn while on the job in an environment that has little room for mistakes when dealing with the personal and emotional support of students.

\section{REFERENCES}

Astin, A. W. (1993). What Matters in College? Jossey-Bass.

Banks, B., Burch, T., \& Woodside, M. (2016). Introducing mindfulness and contemplative pedagogy as an approach to building helping skills in human services students. Journal of Human Services, 36(1), 47-60.

Baxter, P., \& Jack, S. (2008). Qualitative case study methodology: Study design and implementation for novice researchers. The Qualitative Report, 13(4), 544-559. https://nsuworks.nova.edu/tar/vol13/iss4/2

Becker, G. G., Martin, L., Wajeeh, E., Ward, J., \& Shern, D. (2002). Students with mental illnesses in a university setting: Faculty and student attitudes beliefs, knowledge, and experiences. Psychiatric Rehabilitation Journal, 25(4), 359-368.

Bradberry, L. A. \& De Maio, J. (2018). Learning by doing: The long-term impact of experiential learning programs on student success. Journal of Political Science Education, 15(1), 94111. https://doi-org.ezproxy.fgcu.edu/10.1080/15512169.2018.1485571

Burkard, A., Cole, D. C., Ott, M., \& Stoflet, T. (2004). Entry-level competencies of new student affairs professionals: A delphi study. NASPA Journal, 42(3). 283-309. https://doi.10.2202/1949-6605.1509

Burke, M. G., Sauerheber, J. D., Hughey, A. W., \& Laves, K. (2016). Helping skills for working with college students: Applying counseling theory to student affairs practice. Routledge.

Burwell, S. M. (2018). Generation stress: The mental health crisis on campus. Foreign Affairs, 97(6),150-157.

https://search.ebscohost.com.exproxy.fgcu.edu/login.aspx?direct=true\&db=bsu\&AN=1 32341983\&site=eds-live

Carr, W., Wei, Y., Kutcher, S., \& Heffernan, A. (2017). Preparing for the classroom: Mental health knowledge improvement, stigma reduction and enhanced help-seeking efficacy in Canadian preservice teachers. Canadian Journal of School Psychology, 33(4), 314326. https://doi.org/10.1177/0829573516688596

Creswell, J. W. (2013). A case study. In quality inquiry \& research design: Choosing among five approaches ( $3^{\text {rd }}$ ed.). Sage.

Creswell, J. W., \& Poth, C. N. (2018). Qualitative inquiry and research design: Choosing among five approaches ( $4^{\text {th }}$ ed.). Sage.

DiRamio, D.C. (2014). Professional competencies and standards of practice: The student affairs perspective from the Student Affairs Administrators in Higher Education, College Student Educators International, and Council for the Advancement of Standards in Higher Education. In S. Freedman, L.S. Hagedorn, L. F. Goodchild \& D. A. Wright (Eds.), 
Advancing higher education as a field of study: In quest of doctoral degree guidelines (pp.77-92). Stylus.

Forman, J. \& Damschroder, L. (2007). Qualitative content analysis. In L. Jacoby \& L. A. Siminoff (Eds.), Empirical methods for bioethics: A primer, 11. 39-62. https://doi:10.1016/S14793709(07)11003-7

Francis, P. C., \& Horn, A. S. (2017). Mental health issues and counseling services in US higher education: an overview of recent research and recommended practices. Higher Education Policy, 30, 263-277.

Gansemer-Topf, A. M. \& Ryder, A. (2017). Competencies needed for entry-level student affairs work: Views from mid-level professionals. College Student Affairs Journal, 35(1), 40-54. September 11, 2019 from Project MUSE database.

Gockel, A., \& Burton, D. L. (2014). An evaluation of prepracticum helping skills training for graduate social work students. Journal of Social Work Education, 50(1), 101-119.

Hall, K. E. (2009). Anxiety and counseling self-efficacy among counseling students: The moderating role of mindfulness and alexithymia. Dissertation Abstracts International Section A, 70, 1567.

Hill, C. E. (2014). Helping skills: Facilitating exploration, insight, and action (5 $5^{\text {th }}$ ed.). American Psychological Association.

Hill, C. E., Stahl, J., \& Roffman, M. (2007). Training novice psychotherapists: Helping skills and beyond. Psychotherapy: Theory, Research, Practice and Training, 44(4), 364-370. https://doi:10.1037/0033-3204.44.4.364

Hussein, A. (2009). The use of triangulation in social sciences research: Can qualitative and quantitative methods be combined? Journal of Comparative Social Work, 4(1), 1-12. https://journal.uia.no/index.php/JCSW/article/view/212

Jaeken, M., Brison, C., Broeck, N. V., Mikolajczak, M., Verhofstadt, L. L., \&; Zech, E. (2017). Helpers' self-assessment biases before and after helping skills training. Frontiers in Psychology, 8, 1-13. https://doi:10.3389/fpsyg.2017.01377

Kohlbacher, F. (2006). The use of qualitative content analysis in case study research. Journal of Forum: QualitativeSocialResearch,7(1).

https://exproxy.fgcu.edu/login?url=https://serach.proquest.com/docview/869232470? accountid=10919

Kretovics, M. (2002). Entry-level competencies: What student affairs administrators consider when screening candidates. Journal of College Student Development, 43(6), 912-920.

Kutcher, S., Bagnell, A., \& Wei, Y. (2015). Mental health literacy in secondary schools: A Canadian approach. Child and Adolescent Psychiatric Clinics of North America, 24, 233244.

Kutcher, S., Yifeng, W., Gilberds, H., Ubuguyu, O., Njau, T., Brown, A., \& Perkins, K. (2016). A school mental health literacy curriculum resource training approach: Effects on Tanzanian teachers' mental health knowledge, stigma and help-seeking 
efficacy. International Journal of Mental Health Systems, 10, 1-9.

https://doi:10.1186/s13033-016-0082-6

Lipson, S. K., Brunwasser, S., Eisenberg, D., Hahn, E., \& Speer, N. (2014). Gatekeeper Training and access to mental health care at universities and colleges. Journal of Adolescent Health 55, 612-619. https://doi:10.1016/j.jadonhealth.2014.05.009

Lu, Y., Hill, C. E., Hancock, G. R., \& Keum, B. T. (2020). The effectiveness of helping skills training for undergraduate students: Changes in ethnocultural empathy. Journal of Counseling Psychology, 67(1), 14-24.

https://dx.doi.org.ezproxy.fgcu.edu/10.1037/cou0000404

Martin, G. L., \& Seifert, T. A. (2011). The relationship between students' interactions with students' affairs professionals and cognitive outcomes in the first year of college. Journal of Student Affairs Research and Practice, 48(4), 389-410. https://doi:10.2202/1949-6605.6198

Massey, J., Brooks, M., \& Burrow, J. (2014). Evaluating the effectiveness of Mental Health First Aid Training among student affairs staff at a Canadian university. Journal of Student Affairs Research and Practice, 51(30), 323-336. https://doi:10.1515/jsarp-2014-0032

Mitchell, S.L., Carvalho, A., Darrow, S. A., Haggert, M., Neill, T., \& Uschold, C. (2012). Curriculum infusion as college student mental health promotion strategy. Journal of College Student Psychology, 26(1), 22-38. https://doi:10.1080/87568225.2012.633038

Moss, L. S. (2017). Collaboration, Confidentiality, and Care. American Psychology Association, 54(4), 443-450. https://doi:10.1037/ser0000155

Novotney, A. (2014). Students under pressure. Monitor on Psychology, 45(8), 36.

Okun, B. F.\& Kantrowitz, R. E. (2015). Effective helping: Interviewing and counseling techniques (8th ed.). Cengage Learning.

Oros, A. L. (2007). Let's debate: Active learning encourages student participation and critical thinking. Journal of Political Science Education, 3(3), 293-311. https://doi.org/10.1080/15512160701558273

Protivnak, J. J., Mercer, J. C., \& Paylo, M. J. (2013). The Perceived value of counselor preparation for student affairs professionals. The Journal of Counselor Preparation and Supervision, 5(1), 49-62.

Raymond, C. (2010). Do role-playing simulations generate measurable and meaningful outcomes? A simulation's effect on exam scores and teaching evaluations. International Studies Perspective, 11(1), 51-60. https://doi.org/10.1111/j.1528-3585.2009.00392.x

Reynolds, A. L. (2009). Helping college students: Developing essential support skills for student affairs practice. Jossey-Bass.

Reynolds, A. L. (2011). Helping competencies of student affairs professionals: A Delphi study Journal of College Students Development, 52(3), 362-369.

Reynolds, A. L. (2013). College student concerns: Perceptions of student affairs practitioners. Journal of College Student Development, 54(1), 98-104. 
Reynolds, A. L., \& Altabef, D. (2015). Addressing Helping Competencies in student affairs: Analysis of helping skills course syllabi. Journal of Student Affairs Research and Practices, 52(2), 220-231. https://doi:10.1080/19496591.2015.1018268

Stake, R. E. (2005). Qualitative case studies. In Denzin, N. K. \& Lincoln, Y. S. (Eds.). The SAGE Handbook of Qualitative Research. pp. 443-66. Sage.

Stark, M. D. \& Weinbaum, R. K. (2018). Thriving in the grey: The influence of a solutionfocused approach in student affairs. College Student Affairs Journal, 36(1), 136-149.

Tolleson, A. M., Grad, R., Zabek, F., \& Zeligman, M. (2017). Teaching helping skills courses: Creative activities to reduce anxiety. Journal of Creativity in Mental Health, 12(4), 428439. https://doi:10.1080/15401383.2017.1281186

Trela, K. (2008) Facing mental health crises on campus: The imperative of preparing non counselors. About Campus, 12, 30-32.

Vaismoradi, M., Jones, J., Turunen, H., \& Snelgrove, S. (2016). Theme development in qualitative content analysis and thematic analysis. Journal of Nursing Education and Practice, 6(5), 100-110. https://dx.doi.org/10.5430/jnep.v6n5p100

Yazan, B. (2015). Three approaches to case study methods in Education. The Qualitative Report, 20(2), 134-152. https://nsuworks.nova.edu/tar/vol20/iss2/12/

Yin, R.K. (2014). Case study research: Design and methods ( $5^{\text {th }}$ ed.). Sage. 